\title{
Ergonomics and Surgeon Comfort During Flexible Ureteroscopy
}

\author{
Ibrahim Alnadhari (D) \\ Omar Ali ${ }^{1}$ \\ Osama Abdeljaleel' \\ Venkata Ramana Pai Sampige' \\ Ahmad Shamsodini' \\ Morshed Salah ${ }^{2}$ \\ 'Urology Section, Department of \\ Surgery, Al Wakra Hospital, Hamad \\ Medical Corporation, Al Wakra, Qatar; \\ ${ }^{2}$ Urology Section, Department of \\ Surgery, Hazm Mebaireek General \\ Hospital, Hamad Medical Corporation, \\ Doha, Qatar
}

\begin{abstract}
The technological advancements of flexible ureteroscopy (FURS) and its accessories have resulted in broadening its indications to include the management of complex renal stones, with long operative time. The surgeon's understanding about the ergonomics of the ureteroscopes and their cognizance of the operation theatre layout helps to improve their performance, including the surgical outcomes. This paper will describe the ergonomics that are involved in conducting FURS which in turn will aid in developing a more conducive surgical environment for the surgeon during the procedure, based on scientific literature review and expert opinions in high-volume centres. Proper surgeon position, well-arranged operation theatre layout, monitor and pedal position, anaesthesia type, and surgical team are important factors to decrease musculoskeletal strains for surgeons and increase work efficiency. Different types of flexible ureteroscope have different characters and knowing these special characters leads to better ergonomics during surgery. Robotic-assisted FURS have shown good safety and ergonomics in clinical application.
\end{abstract}

Keywords: flexible ureteroscopy, retrograde intrarenal surgery, urolithiasis, ergonomics, endourology

\section{Introduction}

The technological advancement of flexible ureteroscopes and its accessories have impressively facilitated in expanding the indications of flexible ureteroscopy (FURS) to include the management of large complex kidney stones. Generally, complex surgical procedures require well-organized teamwork in a safe and comfortable environment to achieve good results with minimization of errors and complications. The science of Ergonomics focuses on the broad view of the interaction between the human and work systems, consumer products, and working environments, which will be reflected upon human performance and product usability. ${ }^{1}$ However, it was found that the general awareness amongst surgeons regarding the ergonomic guidelines and principles was only $11 \%{ }^{2}$ The aim of ergonomics is firstly, to harmonize workplace environment to the capacity of the urology team. And secondly, to minimize the stress and eliminate fatigue, which includes injuries associated with muscular fatigue that are mainly caused by poor posture while performing repetitive tasks. ${ }^{3}$

The prevalence of orthopedic complaints among endourologists was $64.2 \%$ including back problems (38.1\%) neck problems (27.6\%), hand problems $(17.2 \%)$, and hip and knee problems (14.2\%). This risk is higher in older endourologists ( $>40$ years), endourologists with an African heritage, longer duration of
Correspondence: Ibrahim Alnadhari

Urology Section, Department of Surgery,

Al Wakra Hospital, Hamad Medical

Corporation, Qatar

Tel +97433403324

Email ibrahimah1978@yahoo.com 
practice ( $>10$ years), and annual caseload of longer duration procedures. ${ }^{4}$ Although ergonomics is assumed to be the same for both endourological procedures and laparoscopic procedures, the ergonomic principles for endourological procedures are poorly characterized, in addition to the lack of knowledge of ergonomics amongst endourologists. $^{5}$

Ergonomics during FURS is focused on the interaction between the surgical team (surgeon, assistant, technicians, nurse or anaesthetist) and the operation room (OR) layout with the appropriate array of instruments. In this review, we will focus on the ergonomics involved during FURS along with the aim to provide comprehensive information for the urologist.

\section{Method}

In this narrative review, we searched in the literature for studies and articles on ergonomics of endourology and flexible ureteroscopy using the following key words "flexible ureteroscopy", "ergonomics", "retrograde intrarenal surgery" and "endourology". The search was done in the Medline and Google Scholar databases. We selected the study types in which the full text was available in English language. This review was carried out in accordance to the ethical principles and that are consistent with the good clinical practice.

\section{Surgeon Position}

Currently, there are no studies that highlight a comparison between the surgeons who work in a standing and seated position when conducting FURS. However, despite the lack of literature in this field, it is important to note that a comfortable position of the surgeon during surgery is an important determinant in working efficiently, which in turn will also result in less musculoskeletal stress. During FURS, most surgeons prefer to work in a standing position for more ease in handling the flexible ureteroscope along with the use of auxiliary instruments. On the other hand, some surgeons prefer to be in a seated position whilst performing the procedure. While in the seated position, lowering the patient's leg on the ipsilateral side will allow the surgeon to view the monitor at eye level (Figure $1 \mathrm{~A}$ and $\mathrm{B}$ ). Additionally, proper body posture is determined by the layout of the OR, this includes; the height of the table, position of the monitor, and location of the pedal. Adjustment of the OR layout is required to allow the surgeon to work comfortably in a standing or sitting position in order to mitigate musculoskeletal complications. ${ }^{6}$
While performing the surgery, the flexible ureteroscope is ideally held by the dominant arm. Okada et al reported the use of non-dominant hand for holding the flexible ureteroscopy if one-surgeon basketing technique is used so the dominant hand can be used for manipulation of the basket. ${ }^{7}$ The surgeon holds the scope slightly adducted to the side of the chest and rotated inward at the shoulder level with the elbow flexed between $40^{\circ}-60^{\circ}$ angle, and the hand grasps the scope with the wrist slightly extended while the thumb is on the lever for controlling the tip movements. The non-dominant hand holds the other end of the scope for manual insertion of the scope. The height of the operating table should be adjusted according to the surgeon's position and height. It should not be too low in order to avoid bending of the back resulting in back strain, and not be too high to avoid forward flexion and raising of the shoulder that leads to shoulder muscles fatigue. ${ }^{8}$

\section{Operating Room Layout}

One of the most important considerations when building an operating room is planning and designing a comfortable working environment. ${ }^{9}$ The endourology operating room needs to be large enough to accommodate the large equipment such as C-arm, laser lithotripsy machines, ultrasound machines, and towers with the monitors. The recommended OR size for endourologic procedure is $7 \times 7 \times 3.5 \mathrm{~m}$ to accommodate these large equipment ${ }^{10}$ Hence, a wellthought-out plan and strategic arrangement of the equipment are formulated in order to harmonize the work, increase efficiency, and minimize the risks during the surgery. ${ }^{11}$ Modern OR are more ergonomic with mobile equipment, towers and flexible monitor carriers in addition to OR integration system, thereby optimizing use of the space and resources. The surgeon stands at the foot end; the anesthesiologist and anesthesia cart are at the head end. Sabnis et al recommended the position of the C-arm fluoroscopy unit in the right side of the patient for the right-sided procedure and the camera, light source, and energy source tower should be on the opposite side of the C-arm except for the Laser machine which should be placed in the opposite side of the C-arm. ${ }^{10}$ Giusti et al suggested the C-arm fluoroscopy to be positioned usually in the left side of the patient, whereas the endoscopic tower on the right side. ${ }^{12}$ Our authors suggested changing the setting depending on the side of the surgery especially if you have ceilingmounted monitors and towers so for right-sided surgery, the surgeon's endo-vision monitor and fluoroscopy monitor to be positioned in the right side of the patient, the C-arm on the left side of the patient, the assistant behind the 


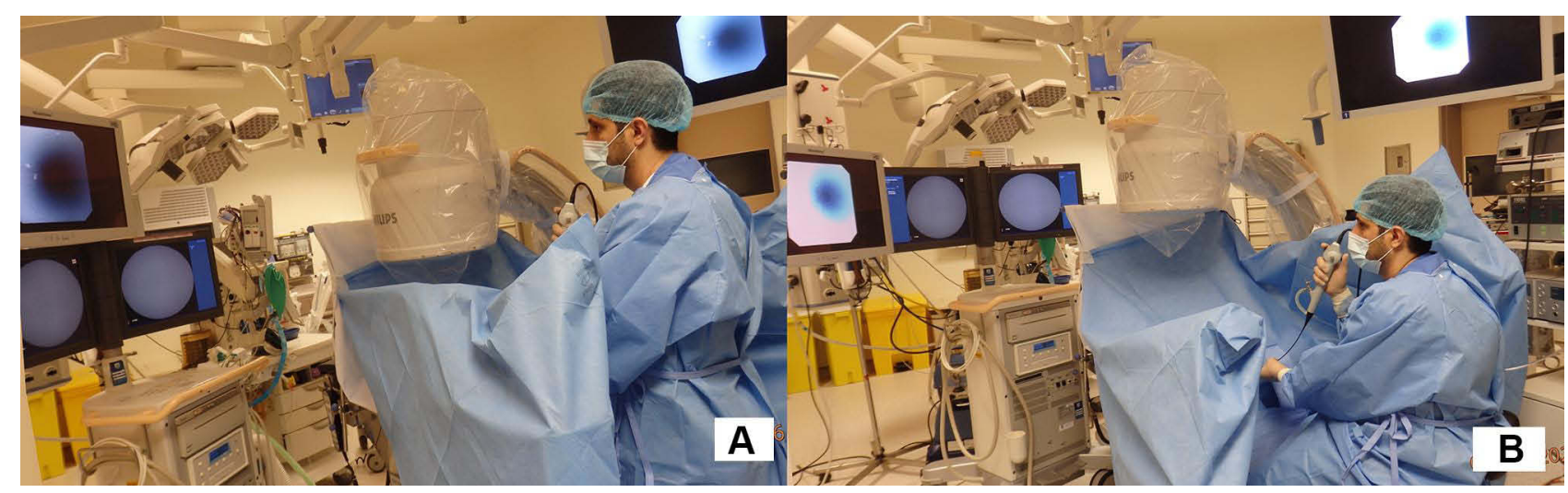

Figure I Surgeon position and operation room layout during flexible ureteroscopy: (A) Standing position, (B) Seated position.

surgeon with additional endo-vision on the left side of the patient. (Figure 2) The camera, light source, and energy source including the laser to be positioned at the feet end on the same side to the $\mathrm{C}$-arm. This setting allowed the surgeon to face the monitors on the same side of surgery in a manner as to not interfere with the $\mathrm{C}$-arm and its operator. Figure 3 showed the scheme for the Operating Room Setup for right-sided surgery.

\section{Position of the Monitor}

The video monitor is another important component during FURS, as prolonged surgeon concentration on an improperly placed monitor can cause strain to the surgeons' eyes, neck, and back muscles. ${ }^{13}$ Fortunately, there are monitors with flexible carriers that provide a free range of movement and adjustment based on individual preference. The position of the monitor should be adjusted at the surgeon's eye level or positioned downward, at an approximate angle of $15^{\circ}$ - in order to ensure that the surgeon looks at the monitor directly without bending the neck either up or down. And, the neck should be in the same alignment with the body without axial rotation of the neck and back. ${ }^{6,8}$ The monitor can be positioned in the middle if the table is digitalized for X-ray, or on the side to allow for the $\mathrm{C}$ arm to be positioned above the

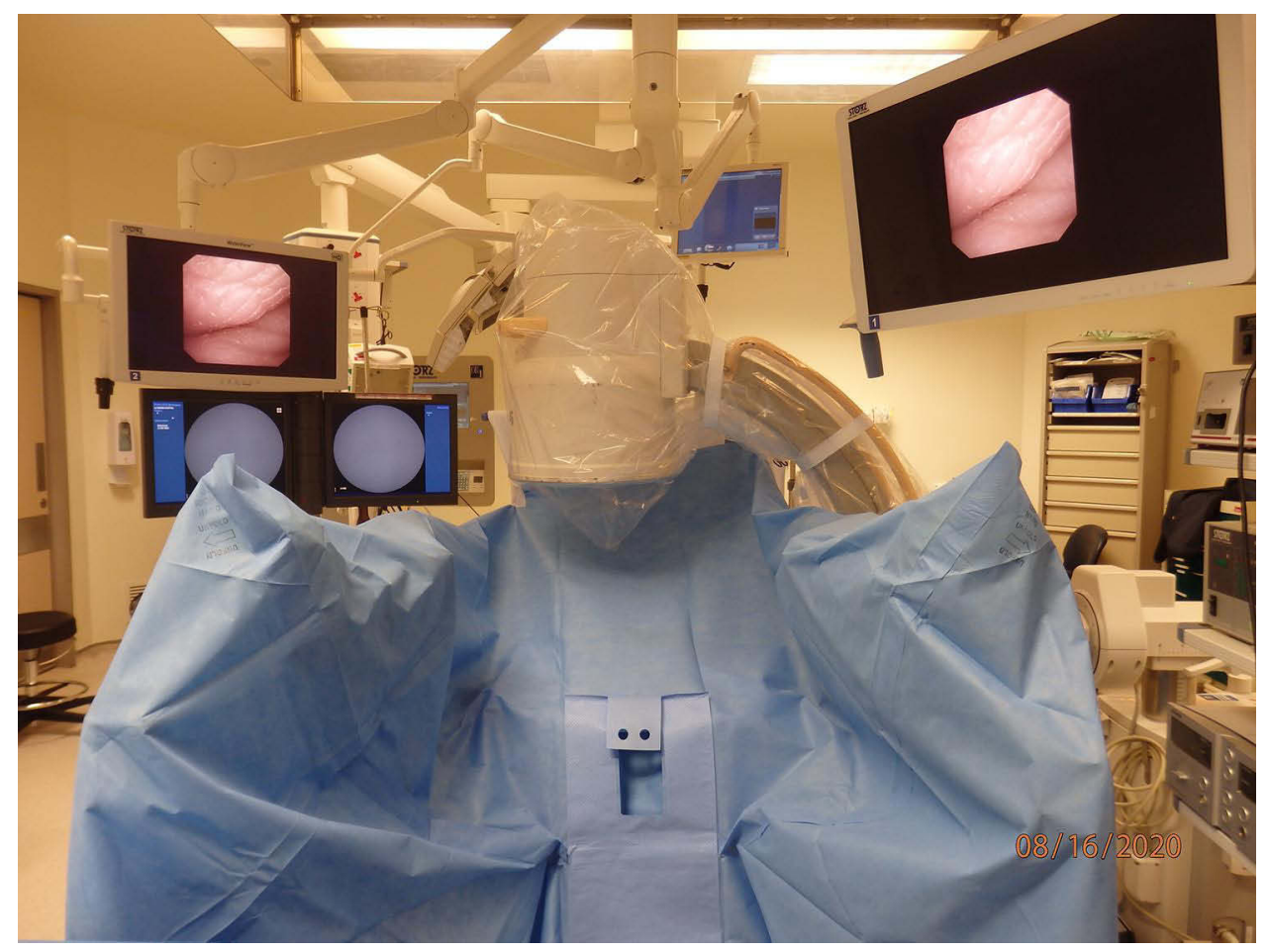

Figure 2 Setup of the operating room, monitors, C-arm and endoscopy tower for the right-sided flexible ureteroscopy. 


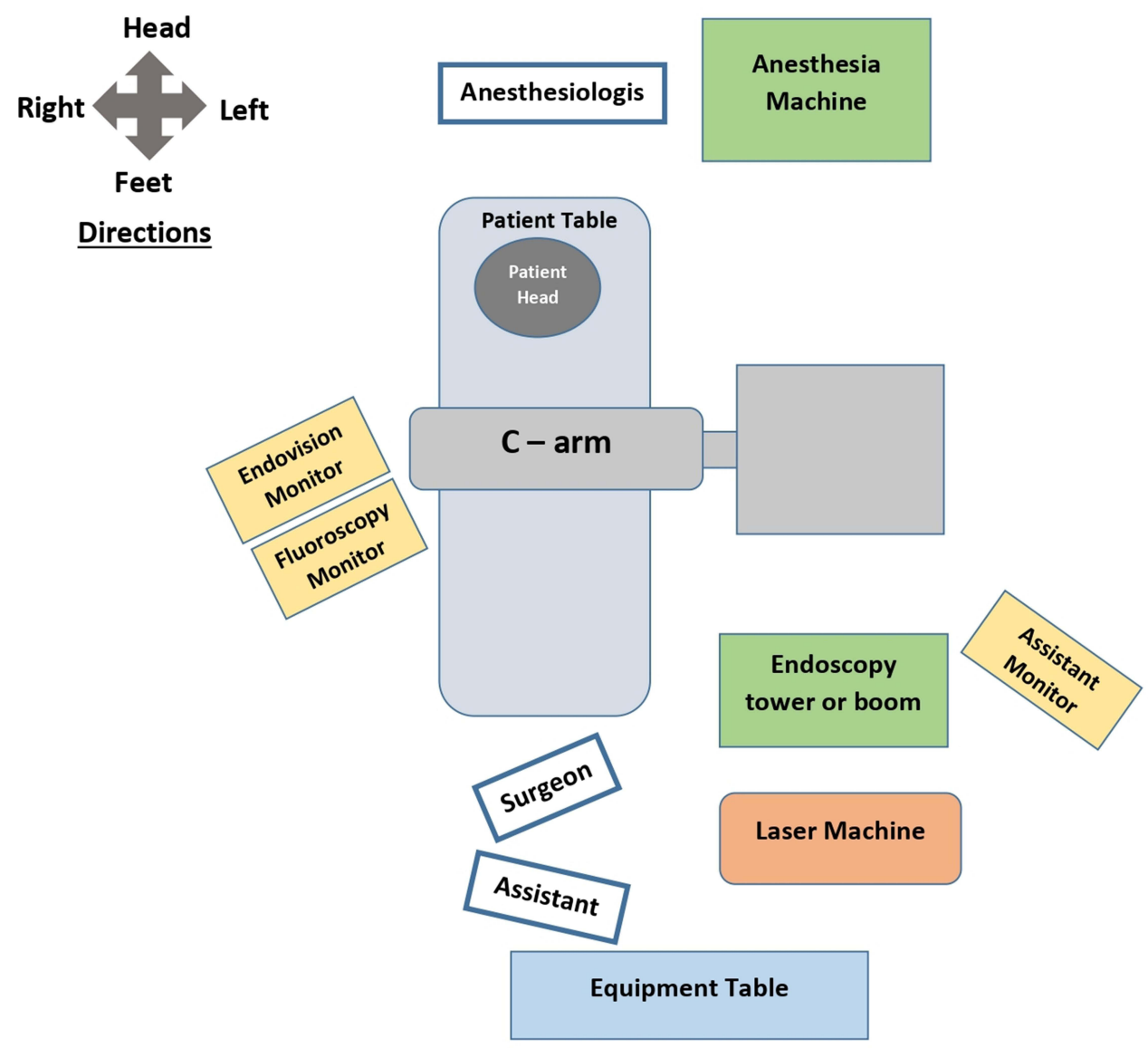

Figure 3 Scheme for the Operating Room Setup for right-sided flexible ureteroscopy.

patient. Moreover, simultaneous arrangement of the fluoroscope monitor, along with the endoscope monitor on the same side of FURS will allow the surgeon look to one side, with the coronal plane of the surgeon being parallel to the coronal plane of the monitors. (Figure 4) This will ensure better hand-eye coordination for the surgeon. The use of ceiling-mounted monitors assists with better arrangement of the monitor's position according to the surgeon's need. Fixed height towers do not provide an adequate range of adjustment to allow ergonomic positioning during FURS. The ceiling-mounted monitors provided the most flexible range of heights, but they are also a common source of "head bumping" by the operating room staff especially during the dimmed light.

The distance between the surgeon's eyes and the monitor is very important so the surgeon can comfortably view the monitor image without straining their eyes. This distance varies on an individual basis and depends on the monitor size. Several studies have been carried out to evaluate the proper monitor-to- surgeon distance. ${ }^{14-17}$ Based on these data and according to the laparoscopic literature, the optimal distance is $80-120 \mathrm{~cm}$; therefore, the orbital and ciliary musculature is in its most relaxed state and facilitates reduced eyestrain on the operator. ${ }^{18} \mathrm{El}$ Shallaly et al recommended a distance of $0.9 \mathrm{~m}$ as the limit of the close-up distance irrespective of other variables. ${ }^{19}$ Sabnis et al recommended the distance between the screen and the surgeon to be five times the diagonal dimension of the screen. ${ }^{10}$ Good image quality provides surgeons with the right depth and colour perception to enable safe and efficient procedures. In comparison, digital ureteroscopes have better image quality than fiber-optic ureteroscopes. ${ }^{20}$ Digital ureteroscopes allows for the options of image enhancement, background noise removal, and colour modification which will be reflected on better outcome especially in detection of tumor, and shorter operative time.

\section{Type of the Scope}

Weight and maneuverability of the scopes differ between the different types of scopes, and this in fact plays a crucial role in incidence of the postoperative strain of 


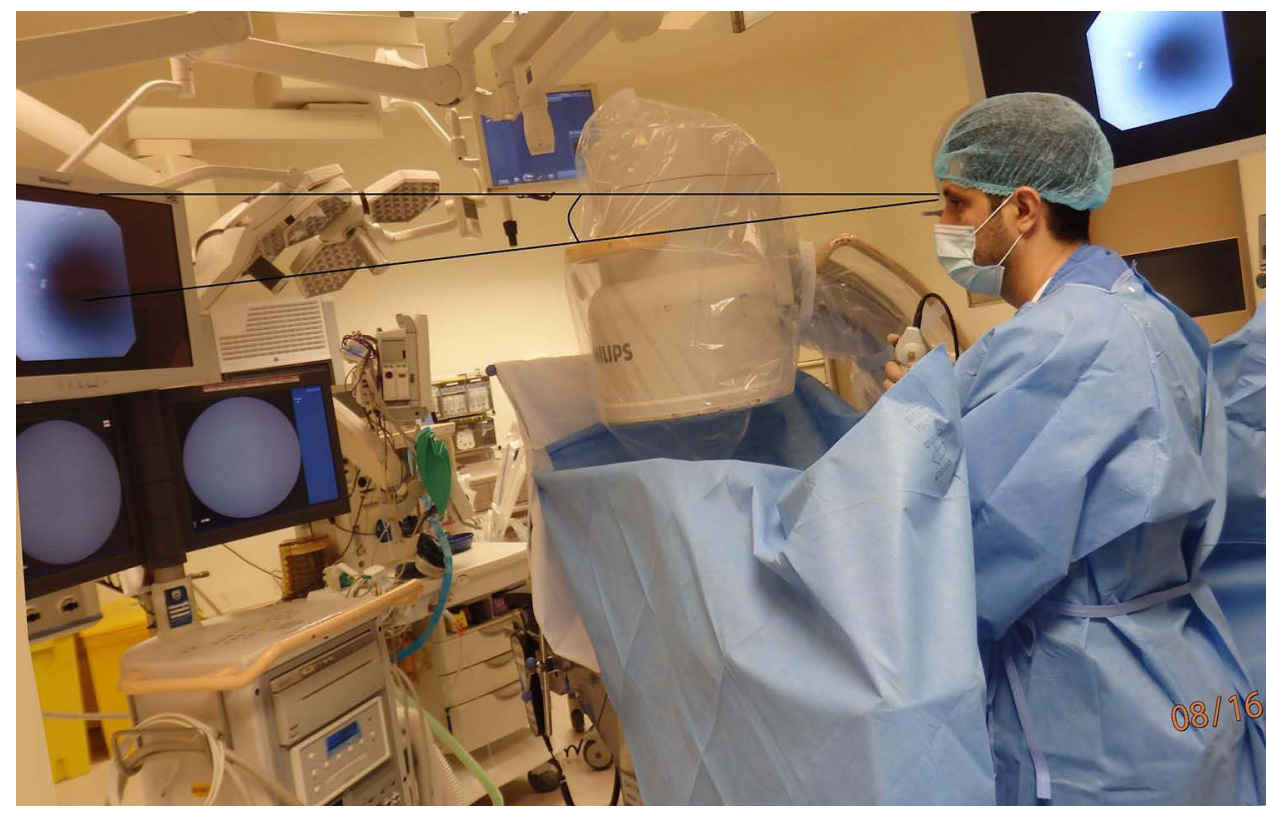

Figure 4 The monitor's level positioned to the surgeon's eye level or approximately $15^{\circ}$ downward.

surgeon's hand, wrist, and thumb strain. ${ }^{21-23}$ Generally, single use ureteroscopes tend to weigh less when compared to digital ureteroscopes. There is also difference in the weights of digital scopes and single use scopes. Single use scope are about 100 gms lighter that the digital scopes for instance a Uscope weighs $220 \mathrm{gms}$ - which is lesser than V2 or flex xc (which weigh around $325 \mathrm{gms}$ ). ${ }^{23,24}$ Digital ureteroscopes are lighter in collation with their fiber-optic counterparts, as the latter tends to hold the additional weight of the camera head. The weight of currently available fiberoptic ureteroscopes varies: 309 to $352 \mathrm{~g}$ (mean $335 \mathrm{~g}$ ) and 278 to $943 \mathrm{~g}$ (mean $700 \mathrm{~g}$ ) for digital ureteroscopes but for fibro-optic ureteroscopes, another 266 to $798 \mathrm{~g}$ (mean $447 \mathrm{~g}$ ) have to be added for the camera head. ${ }^{22,23}$ In a study conducted by Ludwig et al, it was shown that digital ureteroscopes and singleuse ureteroscopes are ergonomically better due to less thumb muscle activity as compared to fiber-optic ureteroscopes. ${ }^{22}$ The types of ureteroscope deflection mechanisms has been studied by Healy et al, where they indicated that intuitive ureteroscope deflection (up is up, down is down) users have less muscular problems in comparison to counterintuitive deflection (up is down, down is up) users. ${ }^{25}$

The exit point of accessory instruments inserted through the working channel plays a role in maneuverability of the scope during the procedure. Theoretically, a scope with an exit point at a 3 o'clock position is more ergonomically suited for the right side since the calyces and stones are located toward the right side and vice versa. $^{21}$ The same concept is applied to the upper and lower calyceal stones. However, it is important to note that some scopes have two different exit ports like COBRA (Richard Wolfe ureteroscope). Regardless of the various types of scopes, it is ideally recommended to have more than one option of scopes. ${ }^{24}$ With the continual technological advancement of single use ureteroscopes, the aforementioned factors can be utilized while customizing and designing right-sided and left-sided scopes in the future.

\section{Irrigation System}

Appropriate irrigation during FURS provides good visibility, more efficacy and comfort. Several irrigation methods systems have been used which include gravity irrigation, pressurized irrigation bags, manual hand-pump infuser, and automated irrigation systems. When comparing the different irrigation method systems, gravity irrigation has less risk of increased intra-pelvic pressure but compromises the visibility. On the other hand, manual pump infuser necessitates an additional task from the surgeon during the procedure. Manual- assisted irrigations systems can be hand-operated irrigation pump as Boston Scientific single action pump and Hand-assisted irrigation device or foot-operated irrigation system as Peditrol. ${ }^{26-28}$ Alternatively, automated irrigation systems have been 
shown to provide steady irrigation at safe pressures with better visibility ${ }^{29-31}$ There are different types of automatic irrigation pumps include Uromat Pump, Thermedx FluidSmart (TFS) ${ }^{\circledR}$ and the Cogentix RocaFlow $(\mathrm{CRF}) \stackrel{\circledR}{{ }^{\circ}} 30$

\section{Foot Pedals}

Foot pedal for laser should be aligned in the proper direction with the posture of the surgeon and directed towards the target or the monitor so that the surgeon does not need to twist the leg for laser activation. (Figure 5A and B). Keeping the pedal near the feet and securing it in steady position prevents its forward migration during its use. This is can be achieved by avoiding covering the foot pedal with a plastic cover so it will be fixed by its rubber push to the floor. Otherwise, if some need to cover it with a plastic cover to avoid rust then it can be stabilized by keeping a heavy object behind it. Poorly positioned pedals can make the surgeon stand in an unnatural twisted position. ${ }^{32}$

\section{Musculoskeletal Disorders During FURS}

According to the US Department of Labour, work-related musculoskeletal disorders are defined as disorders of the muscles, nerves, tendons, joints, cartilage, and spinal disks, which are associated with exposure to risk factors in the workplace. ${ }^{33}$ Analogous to such kind of disorders, during endourology, the most noted complaints related to musculoskeletal strains include the neck, back, shoulder, and wrist. ${ }^{5}$ Similarly, physical strains specifically associated with while performing FURS are of the shoulder, hand, wrist, along with thumb fatigue. ${ }^{25}$ When arranging the specific strains of the muscles- that tend to be heavily relied on during FURS, in a descending order include the extensor carpi ulnaris, followed by right and left thenar, flexor carpi ulnaris, biceps, deltoid, and triceps. ${ }^{22}$ The correct position of shoulder and hand during FURS with proper adjustment of the height of the table can help in minimizing the shoulder and hand fatigue.

$\mathrm{X}$-ray apron is another factor that causes weight burden and musculoskeletal risks during FURS, especially in lengthy procedures. ${ }^{4}$ Instead, the use of skirt and vest ( 2 piece) apron will distribute the weight over the hips and shoulders. ${ }^{34}$

There is direct relation between the time of the surgery and the development of muscular fatigue with decrease in the muscular performance in endourological surgeries with potentially negative consequences on the surgeon and the outcome of the surgery. ${ }^{35}$

There is no recommended time for FURS to minimize the risk of muscular fatigue but there are different factors that can influence the length of FURS including stone size, density of the stone, surgeon and nurse experience,
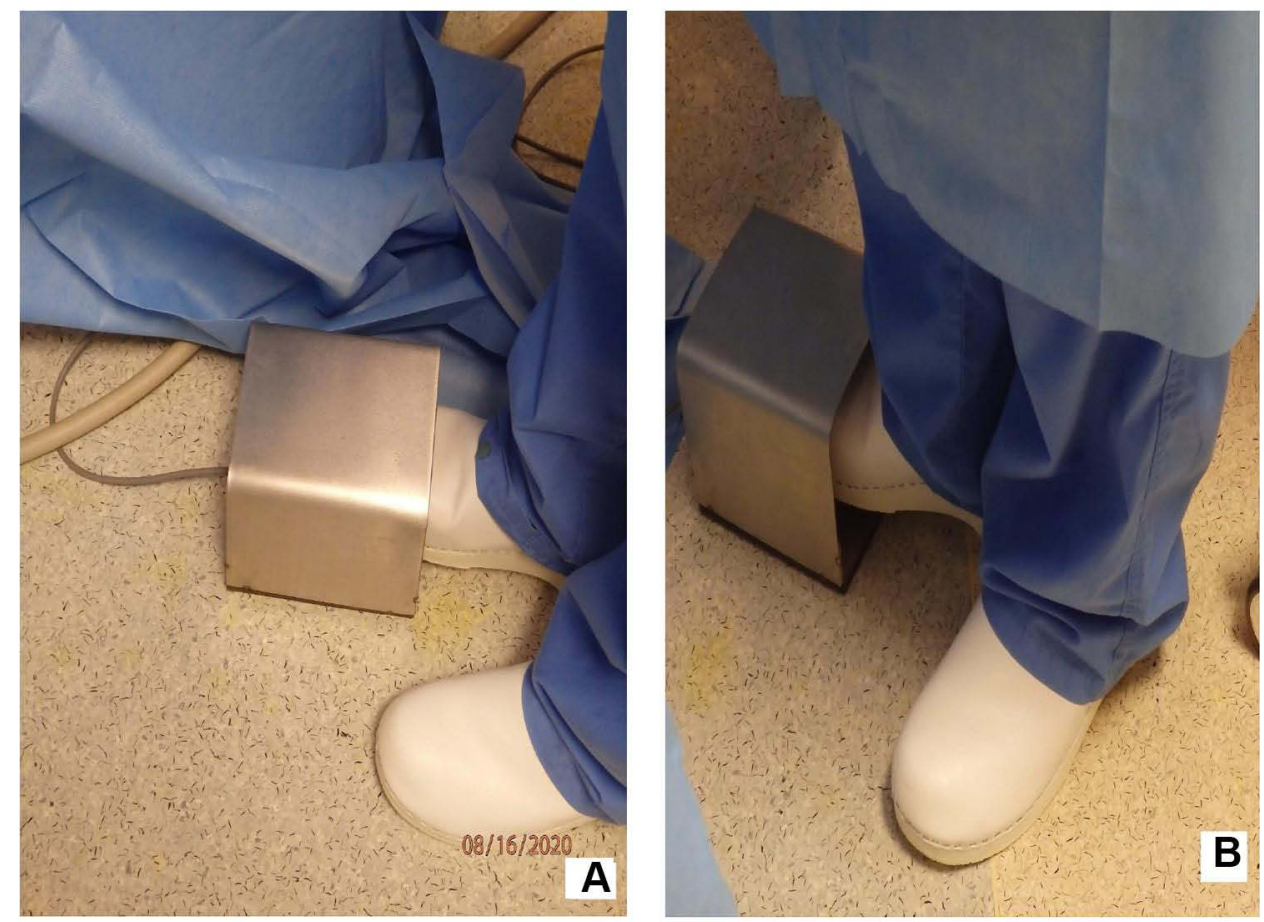

Figure 5 The foot pedal alignment with the surgeon's foot: (A) Correct alignment, (B) Incorrect alignment, leading to rotation of the leg. 
dedicated endourology suite, use of ureteral access sheath and preoperative stent. This information can help to plan the operation theatre day and time. ${ }^{36,37}$

Surgery in general is a demanding activity, and just like sport, it requires mental and physical fitness. Engagement of the surgeons in physical training programs helps to minimize the physical discomfort and improves their performance. ${ }^{38}$

\section{Anaesthesia Type During FURS}

Using an appropriate type of anaesthesia during FURS helps the surgeon carry out the procedure in a far more comfortable manner. Rapid movement of the kidney that is depicted on the monitor during FURS due to increased respiratory rate can disturb the surgeon as the target stone moves simultaneously. This in turn can result in impairing fragmentation of stone, along with the possibility of collateral injury to mucosa of pelvicalyceal system and upper ureter. Different tactics to reduce the kidney movement during general anaesthesia have been used to help the surgeon and increase efficiency. Some of these techniques include the use of periodic apnoea, high-frequency ventilation, and combining high-frequency jet ventilation with small volume mechanical ventilation. ${ }^{39-41}$ FURS can be done under spinal anaesthesia and it is showed that it is safe and effective in comparison to general anaesthesia. ${ }^{42}$ If the patient under spinal anaesthesia is cooperative, they can be asked to take shallow breaths or they can be asked to briefly hold their breathing after deep inspiration or deep expiration at certain moments during FURS that need precise action. ${ }^{43}$ Giusti et al recommended the use of general anesthesia for the reasons of control of the tidal volume during the surgery and the possible exceeding the time frame of spinal. ${ }^{12}$

\section{Surgical Team}

A well-trained team inside the operation theatre is important to deliver efficient and safe FURS. ${ }^{44}$ The operating surgeon, assistant surgeon, anaesthesiologist, surgical tech technician, circulating nurse, and occasionally- a medical device company representative, help the surgeon during the operation. But above all, good communication between the team is the key element in performing a flawless procedure. A dedicated surgical technician scrub nurse should be well informed about the setup of equipment. It is also imperative to have other urology nursing staff members be aware of the basics of the endourology procedures. Additionally, having well-functioning equipment along with its accessory instruments are mandatory for the performance, and minimization of distractions during the surgery. Preoperative planning, preference card, and time out are checkpoints for the preparedness to run the surgery smoothly. An updated preference card is a useful tool to improve the efficiency in the operation theatre. ${ }^{45}$

\section{Robotics FURS}

Robotic-assisted FURS offers significant comfort for the surgeon in terms of physical ergonomics. ${ }^{46}$ The surgeon sits comfortably on the consul chair in an ergonomic working position with digital control of the movement of the scope without straining and twisting their hands and wrists. As a result, the surgeon will be looking directly to the monitor while controlling most of the accessory instruments such as laser, irrigation and fluoroscopy. (Figure 6) Other advantages are provision of space for the assistant beside the patient, and safe distance from the source of radiation (C-arm). Robotic FURS using Avicenna Roboflex ${ }^{\mathrm{TM}}$ showed good safety and ergonomics in clinical application but still there are limitations to the movements along with the need for manual insertion of ureteroscope, laser and other accessory instrument. ${ }^{47,48}$

\section{Radiation Protection During FURS}

During FURS, the patient, surgeon and participating staff members are all at risk of exposure to ionizing radiation. Wearing of protective shields like aprons, thyroid shields, and eyeglasses protect from scattered radiation, but most often it is only partially complied with. Urologists tend to ignore adherence to radiation protection principles due to insufficient awareness. Söylemez et al found that urologists wearing lead aprons, a thyroid shield, eyeglasses, or a dosimeter are $75.2 \%, 46.6 \%, 23.1 \%$, and $26.1 \%$, respectively. ${ }^{49}$ Adherence to the ALARA principles including the three basic protective measures in radiation safety (time, distance, and shielding) are important factors to reduce radiation exposure. ${ }^{50}$

\section{Conclusion}

The expanding indications of flexible ureteroscopy necessitates better efficacy and efficiency during the procedure. Awareness of the ergonomics, knowledge about the instruments and proper arrangement of the operation theatre layout provides a more comfortable working environment for the surgeon, and thereby excel in performance of FURS. 


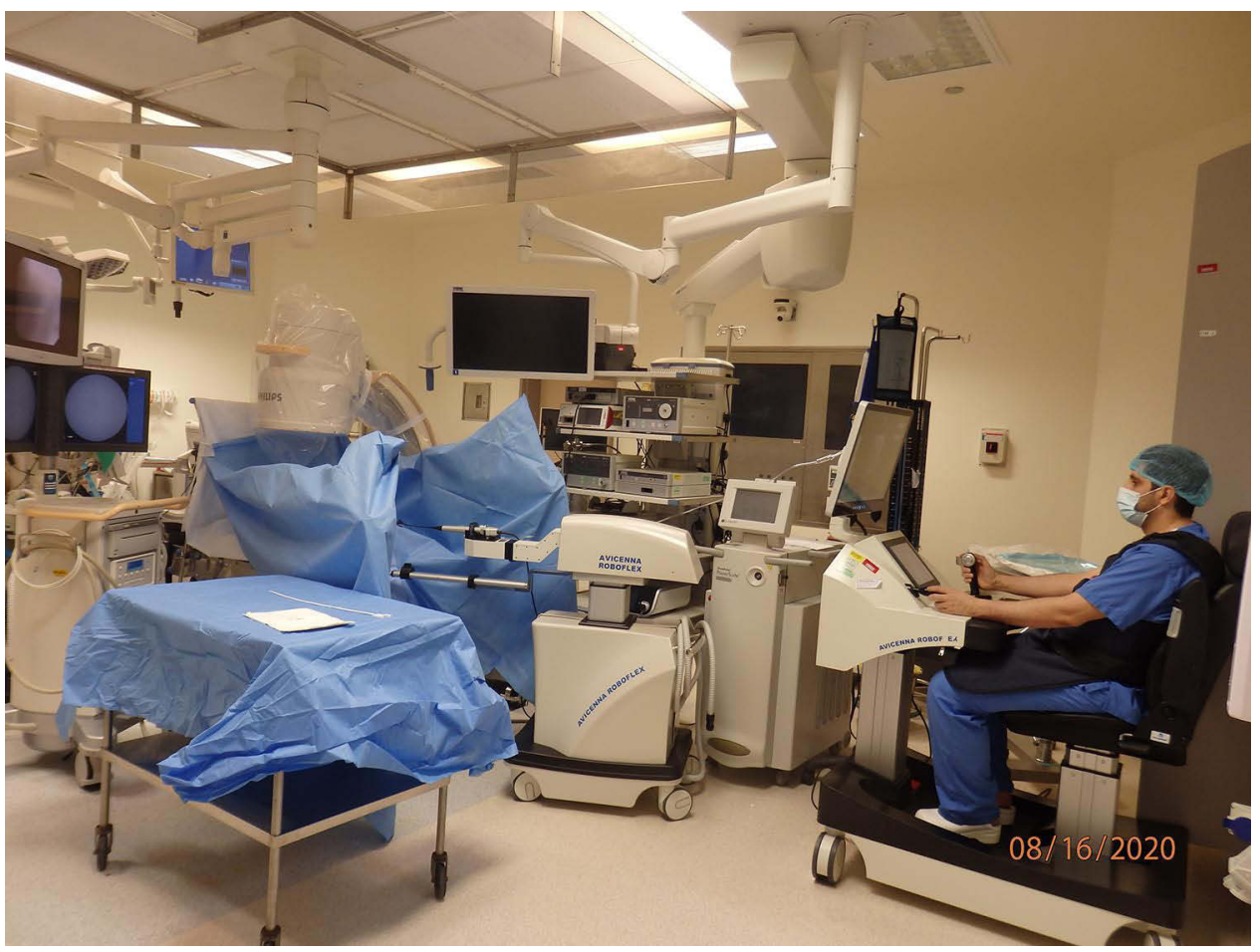

Figure 6 Robotic-assisted flexible ureteroscopy showing the surgeon sitting on the console comfortably.

\section{Abbreviations}

FURS, flexible ureteroscopy; OR, operation room.

\section{Acknowledgments}

Ms. Hala Farid for the for editorial support.

\section{Disclosure}

The authors report no conflicts of interest in this work.

\section{References}

1. Salvendy G. Handbook of Human Factors and Ergonomics. Vol. 2012. New York: Wiley; 1736:xxii.

2. Wauben LS, van Veelen MA, Gossot D, Goossens RH. Application of ergonomic guidelines during minimally invasive surgery: a questionnaire survey of 284 surgeons. Surg Endosc. 2006;20 (8):1268-1274. doi:10.1007/s00464-005-0647-y

3. Bernard BP. U.S. Department of Health and Human Services, Centers for Disease control and Prevention, National Institute of Occupational Safety and Health. Musculoskeletal disorders and workplace factors: a critical review of epidemiologic evidence for work-related musculoskeletal disorders of the neck, upper extremity, and lower back; July 1997. DHHS (NIOSH) Publication No. 97-141. Available from: https://www.cdc.gov/niosh/docs/97-141/. Accessed June 16, 2021.

4. Elkoushy MA, Andonian S. Prevalence of orthopedic complaints among endourologists and their compliance with radiation safety measures. $J$ Endourol. 2011;25(10):1609-1613. doi:10.1089/ end.2011.0109
5. Tjiam IM, Goossens RH, Schout BM, et al. Ergonomics in endourology and laparoscopy: an overview of musculoskeletal problems in urology. J Endourol. 2014;28(5):605-611. doi:10.1089/end.2013.0654

6. Graversen J, Morrison D, Cho J, et al. Ureteroscopy: patient positioning and room setup. In: Monga M, editor. Ureteroscopy. New York: Humana Press; 2013:217-232.

7. Okada S, Hamamoto S, Inoue T, et al. One- versus two-surgeon active stone retrieval procedures for flexible ureteroscopy: an off-site simulator comparative study. Int $J$ Urol. 2021;28 (6):665-671. doi:10.1111/iju.14534

8. Sánchez-Margallo FM, Sánchez-Margallo JA. Ergonomics in laparoscopic surgery. Laparosc Surg. 2017. doi:10.5772/66170

9. Sabnis R, Ganesamoni R, Mishra S, et al. Concept and design engineering: endourology operating room. Curr Opin Urol. 2013;23 (2):152-157. doi:10.1097/MOU.0b013e32835d3133

10. Sabnis RB, Singh A, Mishra S. Organizing the endourological operating room. In: Smith's Textbook of Endourology (eds A.D. Smith, G. M. Preminger, L.R. Kavoussi, G.H. Badlani and A.R. Rastinehad). Vol. 8; Jan 2019: 143-158. doi:10.1002/9781119245193.ch9

11. Sabnis RB, Mishra S, Sharma R, et al. Preoperative planning and designing of a fluorocompatible endourology operating room. $J$ Endourol. 2009;23(10):1579-1585. doi:10.1089/end.2009.1522

12. Giusti G, Proietti S, Villa L, et al. Current standard technique for modern flexible ureteroscopy: tips and tricks. Eur Urol. 2016;70 (1):188-194. doi:10.1016/j.eururo.2016.03.035

13. Vereczkei A, Feussner H, Negele T, et al. Ergonomic assessment of the static stress confronted by surgeons during laparoscopic cholecystectomy. Surg Endosc. 2004;18(7):1118-1122. doi:10.1007/s00464-003-9157-y

14. Brown SI, Frank TG, El Shallaly G, Cuschieri A. Comparison of conventional and gaze-down imaging in laparoscopic task performance. Surg Endosc. 2003;17(4):586-590. doi:10.1007/ s00464-002-8525-3 
15. Omar AM, Wade NJ, Brown SI, Cuschieri A. Assessing the benefits of "gaze-down" display location in complex tasks. Surg Endosc. 2005;19(1):105-108. doi:10.1007/s00464-004-8141-5

16. Matern U, Faist M, Kehl K, et al. Monitor position in laparoscopic surgery. Surg Endosc. 2005;19(3):436-440. doi:10.1007/s00464-0049030-7

17. Haveran LA, Novitsky YW, Czerniach DR, et al. Optimizing laparoscopic task efficiency: the role of camera and monitor positions. Surg Endosc. 2007;21(6):980-984. doi:10.1007/s00464-007-9360-3

18. Van Det MJ, Meijerink WJ, Hoff C, et al. Optimal ergonomics for laparoscopic surgery in minimally invasive surgery suites: a review and guidelines. Surg Endosc. 2009;23(6):1279-1285. doi:10.1007/ s00464-008-0148-x

19. El Shallaly G, Cuschieri A. Optimum view distance for laparoscopic surgery. Surg Endosc. 2006;20(12):1879-1882. doi:10.1007/s00464005-0162-1

20. Talso M, Proietti S, Emiliani E, et al. Comparison of flexible ureterorenoscope quality of vision: an in vitro study. J Endourol. 2018;32 (6):523-528. doi:10.1089/end.2017.0838

21. Keller EX, De Coninck V, Traxer O. Next-generation fiberoptic and digital ureteroscopes. Urol Clin North Am. 2019;46(2):147-163. doi:10.1016/j.ucl.2018.12.001

22. Ludwig WW, Lee G, Ziemba JB, et al. Evaluating the ergonomics of flexible ureteroscopy. $J$ Endourol. 2017;31(10):1062-1066. doi:10.1089/end.2017.0378

23. Proietti S, Somani B, Sofer M, et al. The "Body Mass Index" of flexible ureteroscopes. $J$ Endourol. 2017;31(10):1090-1095. doi:10.1089/end.2017.0438

24. Dragos LB, Somani BK, Keller EX, et al. Characteristics of current digital single-use flexible ureteroscopes versus their reusable counterparts: an in-vitro comparative analysis. Transl Androl Urol. 2019;8 (Suppl 4):S359-S370. doi:10.21037/tau.2019.09.17

25. Healy KA, Pak RW, Cleary RC, et al. Hand problems among endourologists. J Endourol. 2011;25(12):1915-1920. doi:10.1089/ end.2011.0128

26. Farag M, Timm B, Davis N, et al. Pressurized-bag irrigation versus hand-operated irrigation pumps during ureteroscopic laser lithotripsy: comparison of infectious complications. J Endourol. 2020;34 (9):914-918. doi:10.1089/end.2020.0148

27. Doizi S, Traxer O. Flexible ureteroscopy: technique, tips and tricks. Urolithiasis. 2018;46(1):47-58. doi:10.1007/s00240-017-1030-x

28. Blew BD, Dagnone AJ, Pace KT, et al. Comparison of Peditrol Irrigation Device and Common Methods of Irrigation. United States: Mary Ann Liebert, Inc.; 2005:562.

29. Doersch KM, Hart KD, Elmekresh A, et al. Comparison of utilization of pressurized automated versus manual hand irrigation during ureteroscopy in the absence of ureteral access sheath. Proc (Bayl Univ Med Cent). 2018;31(4):432-435. doi:10.1080/ 08998280.2018 .1482518

30. Fedrigon D, Alshara L, Monga M. Comparison of automated irrigation systems using an in vitro ureteroscopy model. Int Braz J Urol. 2020;46(3):390-397. doi:10.1590/S1677-5538.IBJU.2019.0230

31. Inoue T, Yamamichi F, Okada S, et al. Change in irrigation flow through a flexible ureteroscope with various devices in the working channel: comparison between an automatic irrigation pump and gravity-based irrigation. Int $J$ Urol. 2020;27(4):333-338. doi:10.1111/iju.14197

32. Berguer R. Ergonomics in laparoscopic surgery. In: Whelan RL, Fleshman JW, Fowler DL, editors. The SAGES Manual of Perioperative Care in Minimally Invasive Surgery. New York: Springer; 2005:454-464.
33. Barr AE, Barbe MF, Clark BD. Work-related musculoskeletal disorders of the hand and wrist: epidemiology, pathophysiology, and sensorimotor changes. J Orthop Sports Phys Ther. 2004;34 (10):610-627. doi:10.2519/jospt.2004.34.10.610

34. Golan R, Shah O. Performance optimization strategies for complex endourologic procedures. Urology. 2020;139:44-49. doi:10.1016/j. urology.2020.01.033

35. Luttmann A, Jäger M, Sökeland J, et al. Electromyographical study on surgeons in urology. II. Determination of muscular fatigue. Ergonomics. 1996;39:298-313. doi:10.1080/00140139608964460

36. Lane J, Whitehurst L, Hameed BZ, et al. Correlation of operative time with outcomes of ureteroscopy and stone treatment: a Systematic review of literature. Curr Urol Rep. 2020;21(4). doi:10.1007/s11934-020-0970-9

37. Katafigiotis I, Sabler IM, Heifetz EM, et al. Factors predicting operating room time in ureteroscopy and ureterorenoscopy. Curr Urol. 2019;12(4):195-200. doi:10.1159/000499306

38. Giagio S, Volpe G, Pillastrini P, et al. A preventive program for work-related musculoskeletal disorders among surgeons: outcomes of a Randomized Controlled Clinical Trial. Ann Surg. 2019;270 (6):969-975. doi:10.1097/SLA.0000000000003199

39. Emiliani E, Talso M, Baghdadi M, et al. The use of apnea during Ureteroscopy. Urology. 2016;97:266-268. doi:10.1016/j. urology.2016.06.016

40. Galm EK, Harbut P, Freedman J, et al. High frequency jet ventilation for motion management during ablation procedures, a narrative review. Acta Anaesthesiol Scand. 2017;61(9):1066-1074. doi:10.1111/aas. 12950

41. Gadzhiev N, Oibolatov U, Kolotilov L, et al. Reducing kidney motion: optimizing anesthesia and combining respiratory support for retrograde intrarenal surgery: a pilot study. BMC Urol. 2019;19 (61). doi:10.1186/s12894-019-0491-3

42. Zeng G, Zhao Z, Yang F, et al. Retrograde intrarenal surgery with combined spinal-epidural vs general anesthesia: a prospective randomized controlled trial. J Endourol. 2015;29(4):401-405. doi:10.1089/ end.2014.0249

43. Karabulut I, Koc E, Yilmaz AH, et al. Could spinal anesthesia be a choice for retrograde intrarenal surgery. Urol J. 2018;85 (4):169-173. doi:10.1177/0391560318758936

44. KatafigiotisItay I, Sabler IM, Heifetz EM, et al. Factors predicting operating room time in ureteroscopy and ureterorenoscopy. Curr Urol. 2018;12(4):195-200. doi:10.1159/000499306

45. Harvey L, Smith K, Curlin H. Improving operative room costs and efficiency through review of surgeon preference cards. J Minim Invasive Gynecol. 2016;23(7):S37. doi:10.1016/j.jmig.2016.08.097

46. Rassweiler J, Fiedler M, Charalampogiannis N, et al. Robot-assisted flexible ureteroscopy: an update. Urolithiasis. 2018;46(1):69-77. doi:10.1007/s00240-017-1024-8

47. Saglam R, Muslumanoglu AY, Tokatlı Z, et al. A new robot for flexible ureteroscopy: development and early clinical results (IDEAL stage 1-2b). Eur Urol. 2014;66(6):1092-1100. doi:10.1016/j.eururo.2014.06.047

48. Rassweiler JJ, Fiedler M, Charalampogiannis N, Kabakci AS, Sağlam R, Klein JT. Robotics and Ureteroscopy. In: Schwartz F, Denstedt J, editors. Ureteroscopy. Cham: Springer; 2020;239-255.

49. Söylemez H, Altunoluk B, Bozkurt Y, et al. Radiation exposure - do urologists take it seriously in Turkey? J Urol. 2012;187 (4):1301-1305. doi:10.1016/j.juro.2011.11.110

50. Cabrera F, Preminger GM, Lipkin ME. As low as reasonably achievable: methods for reducing radiation exposure during the management of renal and ureteral stones. Indian J Urol. 2014;30(1):55-59. doi:10.4103/0970-1591.124208 


\section{Publish your work in this journal}

Research and Reports in Urology is an international, peer-reviewed, open access journal publishing original research, reports, editorials, reviews and commentaries on all aspects of adult and pediatric urology in the clinic and laboratory including the following topics: Pathology, pathophysiology of urological disease; Investigation and

Submit your manuscript here: https://www.dovepress.com/research-and-reports-in-urology-journal treatment of urological disease; Pharmacology of drugs used for the treatment of urological disease. The manuscript management system is completely online and includes a very quick and fair peer-review system, which is all easy to use. Visit http://www.dovepress.com/ testimonials.php to read real quotes from published authors. 